\title{
$\mathrm{SFM}$ 을 이용한 컨테이너터미널의 효율성 분석
}

\author{
깁운수*·곽규석** \\ *한국해양수산개발원 책임연구원, **한국해양대학교 물류시스템공학과 교수
}

\section{An Analysis on the Efficiency of Container Terminal using Stochesstic Frontier Model}

\author{
Un-Soo Kim* · Kyu-Seok Kwak**
}

*Korea Maritime Institute, Seoul 137-851, Korea

**Department of Logistics Engineering, National Korea Maritime University, Pusan 606-791, Korea

\begin{abstract}
요 약: 최든 심화되고 있는 컨테이너터미널 경쟁에서 각국 항만 및 터미널 운영업체는 터미널의 시설확충 뿐만 아니라 컨테이너터미널 호 율성을 화물유치의 중요한 요인으로 인식하게 되었다. 이러한 환경변화에 따라 컨테이너터미널의 효율성과 관련된 많은 연구가 수행되어 왔었 다. 그러나 대부분의 기존 연구에서는 정성적인 설문조사나 기초테이터률 이용하여 킨테이너터미널에 대한 효율성울 부분적인 관점에서 분석 하거나 단일 연도의 효율성 수준 및 자국 항만의 효율성만울 분석하였다. 따라서 본 연구에서는 확률프론티어 모형 (Stochastic Frontier Model) 을 이용하여 계량적이고, 패널자료률 사용하여 연도벌 호율성의 변화률 실증적으로 분석하여 개별 터미널간의 효율성이 주는 시사점을 도출하 였다. 우리나라 터미널의 효율성 수준은 해외 주요 터미널과 비교해본 결과 경쟁항만에 비해 감만터미널을 제외한 나머지 터미널은 낮은 수준 으로 나타났다.
\end{abstract}

핵심용어 : 효율성, 컨테이너터미녈, 확률 프론티어 모형, 생산함수, 패널자료

Abstract: Recently, global terminal operators are struggling to attract more cargoes into their ports through enlarging facilities and trying to be more efficient operation. Many researches on container terminal efficiency have been conducted, but most of the traditional studies are focused on the partial efficiency of the container terminal using quantitative questionnaires and basic statistical data

In this paper, the Stochastic Frontier Model of the interaction among the variables was employed to execute numerical analysis on the efficiency of terminal. The objective of this paper is to measure the level of efficiency in the container terminals every year and to assess the influence in container terminal's efficiency on domestic and foreign terminals by changing the terminal scales and the level of input factors.

Key words : Efficiency, Container Terminal, Stochastic Frontier Model, Production Function, Panel Data

\section{1. 서 론}

세계 경제블럭의 형성에 따른 세계무역의 증가와 컨테이너화 의 진전 등 국제물류환경이 변화함에 따라 추도권을 선점하기 위한 각 국가간 및 터미널운영업체간의 경쟁이 가중되고 있다. 특히, 중심항의 위상을 선점하기 위한 컨테이너터미넗간의 경 쟁이 더욱 심화되고 있으며, 이에 대한 대응방안으로 항만의 시 설확충 및 화주에 대한 서비스 향상 등을 중점적으로 추진하고 있다.

최근 들어 경쟁하에 있는 대부분의 항만들은 기반시설 확충 및 가격경쟁만으로는 더 이상 중심항 선점을 위한 경갱력을 확 보하는 데에는 한계가 있으며, 컨테이너터미널 효율성을 컨테 이너화물 유치의 필수요인으로 인식하게 되었다. 선사드흘 또한 기항지 선택의 중요요인으로 항만요율 이외에도 서비스 수준 등 호율성의 향상을 요구하고 있다.
그러나 이러한 효율성의 중요성에도 불구하고, 지금까지 컨 테이너터미널의 효율성을 계량적으로 분석한 국내연구는 거의 없는 실정이다. 또한, 기존연구에서는 시간의 흐름에 따른 호율 성 변화를 파악하기보다는 단일 연도의 효율성을 평가하는 데 그치고 있으며, 패널자료를 사용하여 연도별 효율성의 변화 추 세에 대한 구체적인 분석은 없었다.

따라서, 본 논문에서는 연도별 국녜외 컨테이너터미널의 호 율성을 확률프론티어 모델(Stochastic Frontier Model)을 이용 하여 분석하고, 분석결과를 해외 대상 터미널과 비교 - 평가하 여 우리나라 컨테이너터미널의 효율성을 증진시킬 수 있는 방 안을 도출하는 것을 목적으로 한다.

\section{2. 효율성 분석 기존연구}

최근 확률프론티어 모형은 항공산업, 낙농업, 학교 교육, 은

* 대표저자 : 김운수(정회원), luck@kmi.re.kr 02)2105-2833

** 종신회원, kskwak@hhu.ac.kr 051)410-4332 
행, 우체국, 공공기관 및 국가경쟁력에 이르기까지 다양한 분야 에서 광범위하게 응용되고 있다.

확률프론티어 모형은 Aigner et al.(1977)와 Meeusen and Broeck(1977)에 의해 처음 제안되었고, 초기에는 횡단면자료 (Cross-sectional data)를 사용하여 분석되었다. 그러나 비효율 성을 나타내는 변수와 모형에서 사용되고 있는 설명변수, 즉 생 산요소가 서로 독립적이라는 가정이 필요하다는 단점이 있었 다. 이러한 문제점을 보완하기 위해서 Schmidt and Sickles(1984)는 횡단면자료와 시계열자료(Time series data)가 결합된 패널자료(Panel data)를 사용한 모형을 제시하였다. 이 모형은 비효율성의 확률적 분포에 대한 가정을 할 필요가 없으 며, 비효율성 변수와 설명변수간의 독립성 가정도 필요로 하지 않는다는 장점을 가지고 있다.

Notteboom et al.(2000)과 Cullinane et al.(2002) 등이 확률 프론티어 모형에 기초하여 항만의 효율성을 측정하였다. Notteboom et al.(2000)의 연구에서는 유럽항만에서 36개의 터 미널에 대한 효율성을 측정하고, 벤치마킹을 위해 아시아 주 요 터미널을 함께 고려하였지만 단일 연도의 효율성 수준만을 분석하였다. 또한 Cullinane et al.(2002)는 횡단면 자료와 패널 자료를 이용하여 관리형태와 규제완화에 따른 효율성의 변화 를 분석하였고, 대상항만을 아시아권 항만만을 한정하였다.

그 외 항만효율성에 대한 연구로는 이스라엘의 20 개 항만 을 대상으로 항만성과에 영향을 미치는 다양한 요인들을 분석 한 Hayuth and Roll(1993)의 연구가 있으며, 보다 최근 연구 로는 1993 1997년 기간 동안 26개 스페인 항만에 DEA분석 방법을 적용한 Martinez et al.(1999)와 오스트리아 항만과 기 타 세계항만의 효율성을 측정한 Tongzon(2001), DEA/AHP를 이용하여 컨테이너터미널의 효율성을 연구한 송재영(2000)과 스페인 27 개 항만의 자본비용에 대한 효율성을 추정한 Pino and Alvarez(2000) 등이 있다.

이처럼 지금까지 여러 학자들이 항만의 효율성에 대해 많 은 연구를 수행해 왔음에도 불구하고, 단일연도의 효율성 수 준 분석, 자국 항만터미널 및 인근 항만을 대상으로 분석하였 다. 또한, 설명변수에 대한 데이터 수집의 제약으로 안벽, 야 드, 장비 등 전반적인 항만의 호율성에 영향을 미치는 요인들 을 분석하는 데는 한계가 있었다.

\section{3. 분석모형 설계}

\section{1 변수정의}

계량경제학에서 효율성을 평가하기 위한 확률프론터어 생 산함수 모형에서는 투입요소로서 노동과 자본을 일반적으로 사용하고 있다. 컨테이너터미널의 경우에도 노동과 자본을 투 입변수로 처리랑을 종속변수로 하여 효율성을 추정한 연구가 일부 수행되었다. 그러나 각 항만의 개별 컨테이너터미널 운 영자들은 터미널의 경쟁력 강화 및 내부보안 등의 사유로 정 확한 터미널 현황자료와 재무자료 둥을 외부에 공개하지 않는
것에 따른 자료 수집의 한계로 인하여 경쟁 항만간의 효율성 수준을 비교 분석하지 못했다는 한계점을 가지고 있다. 따라 서 최근에 수행된 컨테이너터미널의 효율성에 관한 연구에서 도 이러한 자료수집의 제약성으로 인해 간접적인 투입요소들 을 고려하여 효율성을 추정하였다.

Dowd and Leschine(1990)는 컨테이너부두의 생산성은 노 동, 장비 및 토지의 효율적인 이용에 달려 있으며, 따라서 생 산성은 이 세 요소의 효율적 이용을 계량화함으로써 측정할 수 있다고 하였다. 또한, 기존의 항만경쟁력과 관련된 연구에 서도 컨테이너터미널의 경쟁력을 결정하는 요인으로 항만시설 및 장비 보유현황, 컨테이너부두의 생산성, 가격경쟁력 및 서 비스 측면 둥을 주요 요인으로 들었다(한국컨테이너부두공단, 2002). 그리고 컨테이너터미널 운영에 종사하고 있는 실무전문 가를 대상으로 한 조사 결과에서는 하역장비, $\mathrm{CY}$ 면적, 정보시 스템, 운영인력, 안벽길이, 터미널 총면적 둥이 터미널의 효율 성을 결정하는 중요한 요인으로 평가되었다.

따라서 본 연구에서는 컨테이너터미널의 효율성에 영향을 미치는 요인 중 자료수집의 제약성으로 인해 직 - 간접방식을 통하여 사용되는 변수들을 선정하였다.

첫째, 노동을 대체하는 변수로 장비대수를 선정하였다. 실 제 터미널의 운영에 있어서 장비운영과 관련된 운영인력의 비 중은 55\% 76\%로 높은 점유율을 차지하고 있다. 대부분의 기 존 연구에서는 모든 하역장비를 통합하여 하나의 변수로 적용 하였거나 $\mathrm{T} / \mathrm{C}$ 를 독립된 변수로 적용하지 않았지만, 실질적인 터미널 운영에 있어서는 안벽능력은 $\mathrm{G} / \mathrm{C}$ 가 좌우하며, 야드능 력은 $\mathrm{T} / \mathrm{C}$ 가 좌우하기 때문에 본 논문에서는 보다 현실적인 효율성 측정을 위해 각각의 장비를 투입변수로 선택하여 적용 하였다.

둘째, 자본요소로는 터미널총면적, 안벽길이, 야드면적, CFS 면적 등으로 나타낼 수 있다. 기존 연구에서는 야드면적의 경 우와 터미널 총면적을 각각 투입변수로 간주하였다. 그러나 본 연구에서는 터미널에서 실제 적용되고 있는 야드만을 기준 으로 삼기 위하여 TGS를 적용하였다. 이는 각 터미널마다 사 용되고 있는 야드장비 및 야드 운영형태에 따라 단적 수가 상 이하기 때문에 정확한 야드장치 능력을 적용하기 위해서는 공 통적인 최대 적치능력을 기준으로 TEU로 환산하여 적용하는 것이 바람직하다 할 수 있다.

또한, 산출변수로는 항만에서 처리되는 물동량의 총량 $(\mathrm{R} / \mathrm{T})$, 매출액, 화물형태, 기항선박 수 등 다양하게 나타날 수 있다. 특히, 컨테이너터미널의 경우 총처리량(TEU), 적공컨테 이너 처리량, 매출액 등의 요소 가운데 컨테이너터미널 경쟁 력과 가장 밀접하고, 대외적으로 비교분석이 용이한 총 처리 량이 가장 일반화되어 있다.

따라서, 본 연구에서는 컨테이너터미널의 효율성 분석을 위 한 투입변수로 각 터미널의 물리적인 특성 중 공통적인 자료 를 수집할 수 있는 터미널 총면적, 안벽길이, TGS, G/C수, $\mathrm{T} / \mathrm{C}$ 수를 사용하였으며, 산출변수로는 투입변수와 가장 밀접하 게 관련을 가지고 있는 컨테이너처리량을 사용하였다. 


\section{2 분석자료 수집}

분석 대상 터미널의 자료수집에 있어서 가장 중요한: 점은 자료의 공정성 및 정확성이 필수적으로 확보되어야만 한다는 점이다. 따라서, 국내 컨테이너터미널의 분석자료 수짙은 각 터미널의 내부자료, 홈페이지 활용 및 한국컨테이너부두공단 에서 발간한 연도별 시설현황자료롤 바탕으로 하였으며, 해외 컨테이너터미널의 자료는 Containerisation International Yearbook (1999-2003)을 활용하였다. 그러나 일반적으로 세계 주요 터미 널의 자료는 자료의 누락, 오류, 연도별 일치성에 대한 문제가 발생되기 때문에 본 연구에서는 대상 터미널의 홈페이지 및 이메일 동을 통해 수집된 자료롤 수정-보완하여 최대한 정확 성이 보장된 자료롤 사용하였다. 대상기간으로는 1998년부터 2002년까지 5개년의 패널자료롤 사용하었다.

분석대상 자료는 32 개 터미널의 5 개년 자료 총 150 개이며, 기본적인 통계량은 Table 1과 같다. 전체 물동량 평균은 1,855 천 TEL이며, 평균 안벽길이는 $1,555 \mathrm{~m}$ 이다. 그리고 평궈 장비 대수는 $\mathrm{G} / \mathrm{C}$ 14대, T/C 44대로 나타났다.

Table 1 Statistics of the Object Terminal

\begin{tabular}{|c|c|c|c|c|}
\hline 변수 & 평균값 & 표준편차 & 최소값 & 최대값 \\
\hline 물동량(TEL) & $1,855,110$ & $2,904,700$ & 107,968 & $1,7040,000$ \\
\hline 안벽길이 $(\mathrm{m})$ & $1,555.4$ & $1,730.2$ & 300 & 9,621 \\
\hline 터미널면적 $\left(\mathrm{m}^{2}\right)$ & 658,005 & 665,688 & 105,000 & $3,391,000$ \\
\hline TGS & $43,101.3$ & $48,252.2$ & 6,568 & 263,176 \\
\hline 안벽크례인 대수(개) & 14.4 & 20.9 & 2 & 118 \\
\hline 야드크레인 대수(개) & 43.6 & 64.9 & 4 & 375 \\
\hline
\end{tabular}

\section{3 분석모형 설계}

수집된 자료의 분석 및 확률프론티어 생산함수 모형의 설 정과 효율성 촉정을 위하여 계량경제 전용 소프트웨어인 LIMDEP 7.0을 이용하였다. LIMDEP에서 사용되는 확혼프론 티어 생산함수 모형은 다음의 식 (1)과 같다.

$$
y_{i t}=X_{i t} \beta+v_{i t}-u_{i t}, i=1, \ldots \ldots, N, t=1, \ldots \ldots, T
$$

$y_{i t}=t$ 기간동안 $i$ 번째 기업의 산출

$X_{i t}=t$ 기간동안 $i$ 번째 기업의 요소투입량

$\beta=$ 생산함수의 계수 행렬

$v_{i}=$ 정규분포 $N\left(0, \sigma_{v}^{2}\right)$ 롤 가지며 $u_{i}$ 와 독립적인 확롤변수

$u_{i}=$ 비효율성을 설명하며 정규분포 $N^{+}\left(0, \sigma_{u}^{2}\right)$ 롤 따트는 비음

의 확률변수

이 모형에서 $u_{i}$ 가 가지고 있는 의미는 최대생산량 $X_{i t} \beta+v_{i}$ 로부터의 생산랑 $y_{i t}$ 의 손실을 나타내며, 이것은 개 별기업 $i$ 에 있어 다양한 비효율성을 의미하는 것이다. 만약 $u_{i}=0$ 이라면 식 (1)은 일반적인 회거분석에 사용되츤. 생산함
수와 같다.

본 연구에서는 Cobb-Douglas 프론티어생산함수에 패널자 로롤 이용하여 효율성을 추정하였다. 패널자로는 기술적 비효 율성을 측정함에 있어서 관찰치가 반복되어 사용되기 때문에 톡정한 분포를 가정하지 않아도 되며, 반복되는 관측자로로 인하여 회귀자(Regressor)에 대하여 독립이라는 가정을 하지 않아도 된다. 또한, 횡단면 자료에서는 얻을 수 없는 여러 가 지 유용한 정보롤 획득할 수 있다는 장점을 가지고 있다. 이 러한 패넓자료를 이용한 효율성의 추정식은 다음의 식 (2)와 같이 표현할 수 있다.

$$
\begin{aligned}
& T E U_{i t}=e^{v_{t i}} e^{-u_{i t}} \alpha B_{i t}^{\beta_{B}} G_{i t}^{B_{G}} C_{i t}^{\beta_{C}} T_{i t}^{\beta_{T}}, i=1, \ldots, N, \\
& t=1, \ldots T
\end{aligned}
$$

$T E U=$ 컨테이너처리랑

$B=$ 투입된 안벽길이

$G=$ 투입된 TGS 수

$C=$ 투입된 $\mathrm{G} / \mathrm{C}$ 수

$T=$ 투입된 $\mathrm{T} / \mathrm{C}$ 수

$i=$ 컨테이너터미널

$t=$ 시간(연도)

$\alpha=$ 상수

식 (2)에 자연대수롤 취하면, 식 (3)과 같은 실제 추정식을 구할 수 있다.

$\ln T E U_{i t}=\alpha+\beta_{B} \ln B_{i t}+\beta_{G} \ln G_{i t}+\beta_{C} \ln C_{i t}+\beta_{T} \ln T_{i t}+v_{i t}-u_{i t}$

비효율성을 나타내는 $u_{i t} \sim N\left(u_{i t}, \sigma_{u}^{2}\right)$ 의 분포를 따르고, 확 폴적 오차롤 나타내는 $v_{i t}-N\left(0, \sigma_{v}^{2}\right)$ 의 분포를 따른다. $e^{v_{t i}}$ 는 $(0, \infty)$ 의 값을 가지며, $e^{-u_{t}}$ 는 $(0,1)$ 의 값을 가진다. 만약 $u_{i}=0$ 이라면, $e^{-u_{i}}=1$ 이며, 이것은 생산이 완전히 효율적이 라는 것을 의미한다. 즉, 효울성 지표인 $e^{-u_{i}}=0.8$ 이라면 컨테 이너터미넗의 실제 산출은 최대가능생산량의 $80 \%$ 를 달성하고 있으며, $20 \%$ 는 비호율성으로 인한 손실이 발생하고 있음을 의 미하는 것이다. 따라서 $e^{-u_{i}}$ 는 효율성 지표로 $u_{i}$ 는 비효율성 지표로 간주할 수 있다.

Battese and Coelli(1988)는 횡단면 자료에서 조건부 기대값 을 이용하여 비효율성을 추정하는 Jondrow et al.(1982)의 방 법을 패널자료에서의 효율성을 측정하기 위한 방법으로 주어 진 $\epsilon_{i t}$ 로부터 비효율성 지표인 $u_{i}$ 와 효-율성 지표인 $e^{-u_{i}}$ 의 조 건부 기대값을 다음의 식 (4)와 같이 일반화하였다.

$$
E\left(u_{i} \mid \epsilon_{i}\right)=\mu_{i}^{*}+\sigma_{*} \frac{\phi\left(-\mu_{i}^{*} / \sigma_{*}\right)}{1-\Phi\left(-\mu_{i}^{*} / \sigma_{*}\right)}
$$

여기서, $\sigma_{*}^{2}=\frac{\sigma_{u}^{2} \sigma_{v}^{2}}{\sigma_{v}^{2}+T \sigma_{u}^{2}}, \mu_{*}=-\frac{T \sigma_{u}^{2} \bar{\epsilon}}{T \sigma_{u}^{2}+\sigma_{v}^{2}}, \overline{\epsilon_{i}}=\frac{1}{T} \sum_{t} \epsilon_{i t}$ 
따라서 식 (4)를 통하여 확률프론티어 함수로부터 투입과 산출에 관련된 기업의 비효율성을 측정할 수 있다.

개별 터미널 $i$ 의 평균효율성 $\left(T E_{i}\right)$ 은 다음의 식 (5)와 같이 최대생산가능량 $\left(u_{i}=0\right)$ 에 대한 실제 생산량의 비율로 정의될 수 있다.

$$
\begin{aligned}
T E_{i} & =\frac{E\left(T E U_{i t} \mid u_{i t}, A_{i t}, B_{i t}, G_{i t}, C_{i t}, T_{i t}, t=1,2, \ldots\right)}{E\left(T E U_{i t} \mid u_{i t}=0, A_{i t}, B_{i t}, G_{i t}, C_{i t}, T_{i t}, t=1,2, \ldots\right)} \\
& =\frac{e^{-u_{i}} \alpha A_{i t}^{\beta_{A}} B_{i t}^{\beta_{B}} G_{i t}^{\beta_{G}} C_{i t}^{\beta_{C}} T_{i t}^{\beta_{T}}}{\alpha A_{i t}^{\beta_{4}} B_{i t}^{\beta_{B}} G_{i t}^{\beta_{i}} C_{i t}^{\beta_{C}} T_{i t}^{\beta_{T}}} \\
& =e^{-u_{i}}
\end{aligned}
$$

개별 터미널의 효율성은 다음의 식 (6)과 같이 구할 수 있 다.

$$
T E_{i}=\left(e^{-u_{i}} \mid \epsilon_{i}\right)=\left\{\frac{1-\Phi \sigma_{*}\left(-\frac{u_{i}^{*}}{\sigma_{*}}\right)}{1-\Phi\left(-\frac{u_{i}^{*}}{\sigma_{*}}\right)}\right\} \cdot \exp \left(-\mu_{i}^{*}+\frac{1}{2} \sigma_{*}^{2}\right)
$$

본 연구에서 대상으로 삼고 있는 컨테이너터미널의 경우 투입요소인 관련 시설-장비, 면적 등에 대하여 산출요소인 컨테이너처리량이 연도별로 변하는 형태이므로 횡단면 자료만 을 사용하는 것보다 패널 자료를 사용하여 분석하는 것이 보 다 정확한 측정이 될 수 있다. 패널분석은 패널자료에 비효율 이 존재한다는 것을 검증하여 확률프론티어 생산함수를 통해 변수간의 분포를 설정하는 과정이다. 즉, 효율성 추정에 사용 되는 패널자료가 내포하고 있는 비호율의 특성을 파악하여 그 특성에 부합하는 모형을 적용하는 것이다.

패널분석기법은 고정효과모형(Fixed Effect Model : FEM) 과 확률효과모형(Random Effect Model : REM)으로 나눌 수 있는데, $\mathrm{FEM}$ 은 $\beta_{t}$ 즉, 개별호과를 일종의 상수항으로 처리하 는 반면에 REM은 개별호과를 오차항의 일부로 처리하는 차 이가 있다. 이러한 두 가지 모형 중 어떤 모형으로 효율성을 추정하는 것이 타당한지의 여부를 결정하는 방법에는 자료의 속성을 기준으로 하는 방법과 Hausman Test를 통해 선택하 는 방법이 있다. 그러나 자료의 속성을 기준으로 선택하는 경 우에는 연구자의 주관적인 측면이 강하게 포함되기 때문에 통 계적으로 검증되지 않는다는 한계점을 가지고 있다. 따라서 본 연구에서는 통계적인 검증이 가능하며, 일반적으로 많이 사용되고 있는 Hausman Test를 이용하여 패널분석을 수행하 였다.

Hausman Test에서는 REM이 더 좋다는 귀무가설하에서 Hausman 검증통계량 $\mathrm{p} \leq 0.1$ 이면 귀무가설을 기각하고 $\mathrm{FEM}$ 으로 추정하는 것이 타당하며, Hausman 검증통계량 $\mathrm{p}>0.1$ 이 면 귀무가설을 채택하여 $\mathrm{REM}$ 으로 추정하는 것이 타당하다고 할 수 있다(박, 김, 2002).

이와 같은 기준으로 Table 2의 분석을 검증해 본 결과 Hausman 검증통계량 $\mathrm{p}=0.0076<0.1$ 인 것으로 나타나 귀무가 설이 기각되어 $\mathrm{FEM}$ 으로 추정하는 것이 타당한 것으로 나타
났다. 즉, 본 연구에서 사용되는 패널자료의 경우 고정효과의 특성을 내포하고 있는 것으로 나타나 효율성을 추정함에 있어 고정효과모형 $(\mathrm{FEM})$ 을 적용하는 것이 바람직한 것으로 분석되 었다.

Table 2 Test result of FEM and REM

\begin{tabular}{|c|c|c|}
\hline 구분 & 분석값 & P-value \\
\hline $\begin{array}{c}\text { FEM에 대한 } \mathrm{F} \text { 검정 } \\
\left(H_{0}: \alpha_{1}=0\right)\end{array}$ & $H_{(5,113)}=13.69$ & 0.0000 \\
\hline $\begin{array}{c}\text { FEM vs. REM에 대한 } \\
\text { Hausman 검정 }\end{array}$ & $\chi^{2}=15.75$ & 0.0076 \\
\hline
\end{tabular}

\section{4. 확률프론티어 생산함수 추정}

\section{1 생산함수 추정결과}

확률프론티어 생산함수를 추정한 결과는 다음의 Table 3에 나타나 있다. 추정결과에 따르면, 최소자승법(OLS)으로 추정 한 Cobb-Douglas 생산함수의 적합도는 $R^{2}=0.927$ 로 나타나 적합성이 양호한 것으로 나타났다. Table 3에 요약한 두개의 오차항에 대한 분산을 살펴보면, Half-Normal 분포에서는 $\sigma_{u}^{2}$ $=0.1988, \sigma_{v}^{2}=0.0149$ 로 추정되어 $\lambda=\sigma_{u}^{2} / \sigma_{v}^{2}=13.39>1$ 로 나 타나 비효율성 오차가 통계적 오차를 압도하여 확률프론티어 모형이 OLS보다 더 바람직한 접근방식인 것으로 나타났다.

투입변수별 추정결과를 살펴보면, $\mathrm{Ln}(\mathrm{G} / \mathrm{C})$ 가 0.745로 컨테 이너터미널의 효율성에 가장 강한 영향을 미치고 있는 것으로 나타났으며, 다음으로 $\operatorname{Ln}(\mathrm{T} / \mathrm{C})$ 가 $0.527, \mathrm{Ln}(\mathrm{TGS})$ 가 0.227 의

\begin{tabular}{|c|c|c|c|}
\hline \multirow{2}{*}{ 변수 } & \multicolumn{3}{|c|}{ MLE } \\
\hline & Half-Normal & Exponential & Truncated \\
\hline 상수 & 12.459 & 13.490 & 12.920 \\
\hline & $(18.774) *$ & $(19.758) *$ & $(18.428) *$ \\
\hline Ln(Berth) & -0.561 & -0.656 & -0.596 \\
\hline & $(-4.959) *$ & $(-5.424) *$ & $(-4.984) *$ \\
\hline $\operatorname{Ln}(T G S)$ & 0.227 & 0.132 & 0.187 \\
\hline $\operatorname{Ln}(\mathrm{G} / \mathrm{C})$ & (3.318)* & $(1.830) * * *$ & $(2.490) *$ \\
\hline Linter & 0.745 & 0.907 & 0.811 \\
\hline $\operatorname{Ln}(\mathrm{T} / \mathrm{C})$ & $(5.481) *$ & $(6.347) *$ & $(5.508) *$ \\
\hline & $\begin{array}{c}0.527 \\
(5819) *\end{array}$ & 0.558 & 0.538 \\
\hline$\theta$ & (5.819)* & $\begin{array}{c}(5.452) * \\
5.056(4.316) *\end{array}$ & (5.433)* \\
\hline $\begin{array}{l}\sigma_{u}^{2}, \sigma_{v}^{2} \\
\mu / \sigma_{u}\end{array}$ & $0.1988,0.0149$ & $0.0391,0.0452$ & $\begin{array}{c}0.1492,0.0224 \\
-0.1945(-0.161)\end{array}$ \\
\hline$\lambda=\sigma_{u} / \sigma_{v}$ & $3.651(3.083) *$ & & \\
\hline $\begin{array}{c}R^{2} \\
\text { Log-likelihood }\end{array}$ & $\begin{array}{c}0.9265 \\
-21.8092\end{array}$ & -22.9818 & -22.0894 \\
\hline
\end{tabular}
순으로 추정되었다. 그러나 $\mathrm{Ln}(\mathrm{Berth})$ 는 음(-)의 계수값을 가 지는 것으로 나타났다.

Table 3 Estimation Result of Production Function

주 : 1) ( )은 $\mathrm{t}$ 값을 의미함.

2) $* \mathrm{p}<0.01$, ** $\mathrm{p}<0.05$, *** $\mathrm{p}<0.1$ 유의수준임. 


\section{2 컨테이너터미널 효율성 추정결과}

확률프론티어 생산함수를 이용한 컨테이너터미널의 연도별 평균효율성을 살펴보면, Fig. 1과 같이 1998년의 경우에 0.670 이며, 1999년 0.694, 2000년 0.747, 2001년 0.772, 2002년 0.812 로 매년 효율성 평균값이 증가하고 있음을 알 수 있다. 이와 같은 이유는 컨테이너터미널의 경우 부두개장과 동시에 투입 요소인 기반시설과 장비가 갖추어져 산출요소인 물동량의 증 가가 효율성의 증가로 이어지고 있기 때문이다.

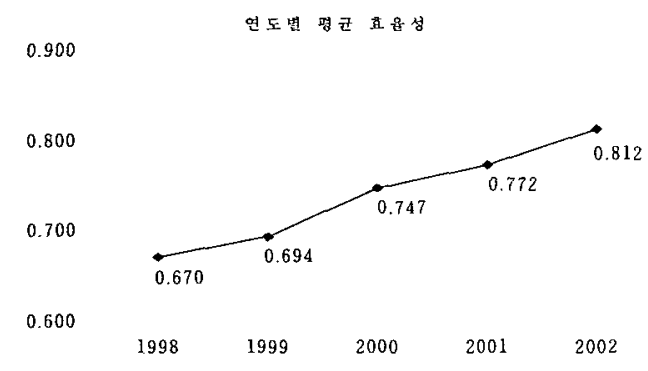

Fig. 1 Efficiency change by year of Analysis

Fig. 2는 효율성과 물동량에 대한 관계 기준을 나타멘 것이 다. 효율성은 높다, 낮다라는 정확한 기준을 설정하기 어럽기 때문에 본 연구에서는 평균값을 도입하여 개별 터미널간의 비 교분석을 실시하였다. Cluster 1은 효율성과 물동량이 평균값 이상을 나타낸 터미널로서 대상 터미널 중에서 최고의 성과를 나타내고 있는 그룹이며, Cluster 2는 효율성은 평균이상이나 물동량이 평균이하인 그룹, 그리고 Cluster 3 은 효율성과 물동 량이 평균을 하회하는 성과가 낮은 그룹이다.

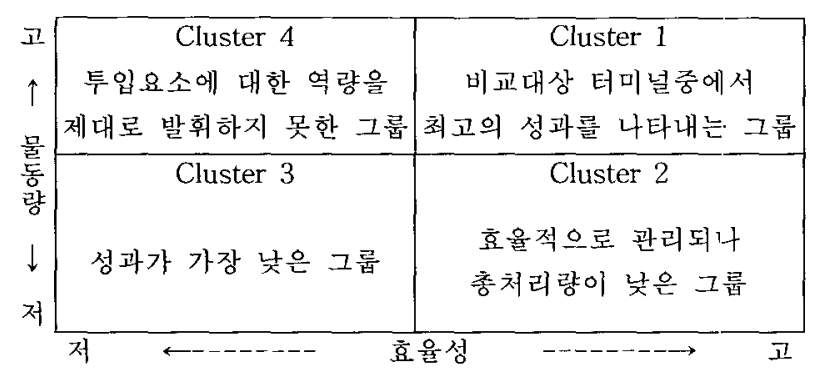

Fig. 2 Relation Matrix Efficiency and Traffic Volume

1999년의 효율성과 물동량의 관계매트릭스에서 Gioia Tauro, Dubai, SCT, HIT, MTL, Singapore, Algeciras 등이 Cluster 1에 포함되어 있다. 우리나라 터미널의 경우 Gamman $\mathrm{HKT}$, Hanjin 및 KEC, Gamcheon 등이 효율성이 높은 Cluster 2에 나타나고 있으며, PECT, HBCT, UTC 및 Gwangyang 터미널은 효율성과 물동량이 낮은 Cluster 3에 포함되어 있다. 이것은 1999년 IMF구제금윰사태로 음(-)의 경 제성장을 기록하여 컨테이너물동량이 소폭 증가에 그친 것에 기인하며, Gwangyang은 신설항만으로서 유치 물동링이 적음 에 그 원인이 있다고 판단된다.

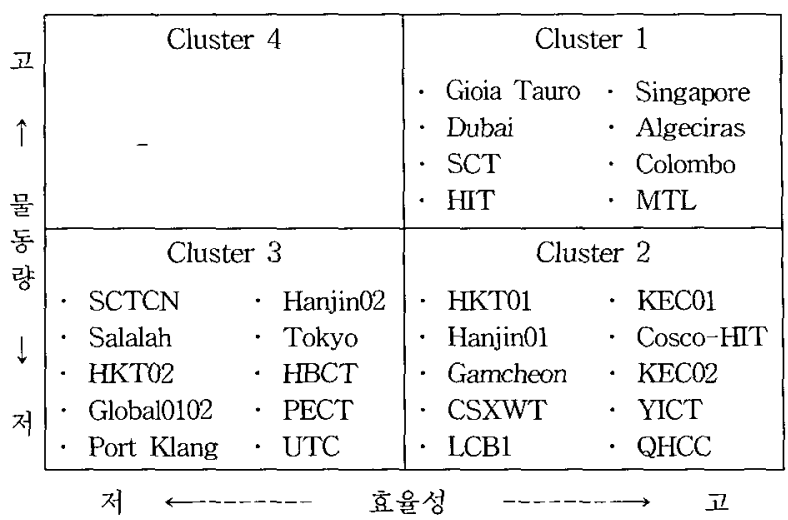

Fig. 3 Relation Efficiency and Traffic Volume(1999)

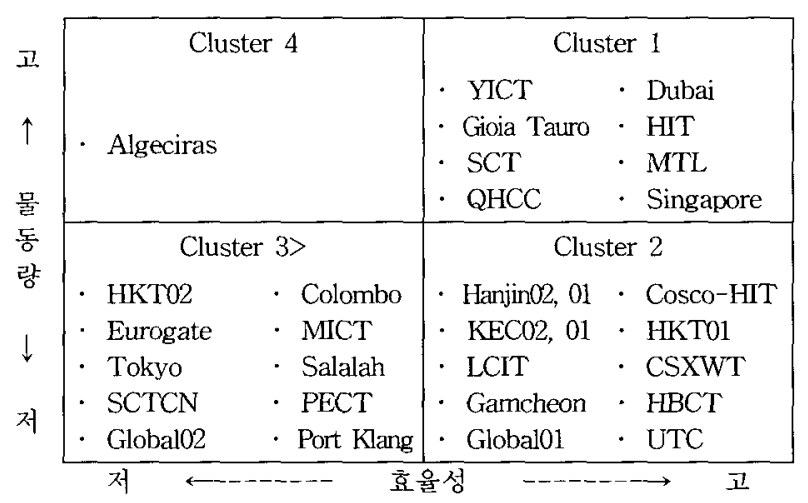

Fig. 4 Relation Efficiency and Traffic Volume(2002)

Fig. 5는 분석된 효율성을 기준으로 우리나라와 아시아 주 요 항만과의 효율성과 물동량의 변화를 나타넨 것이다. 1999 년 평균값 (a)점은 효율성 0.694, 물동량 161만TEU이며, 2002 년 평균값 (b)점은 효율성 0.812, 물동량 207만TEU로 나타났 으며, 대부분의 터미널에서 효율성이 증가하였음을 보여주고 있다.

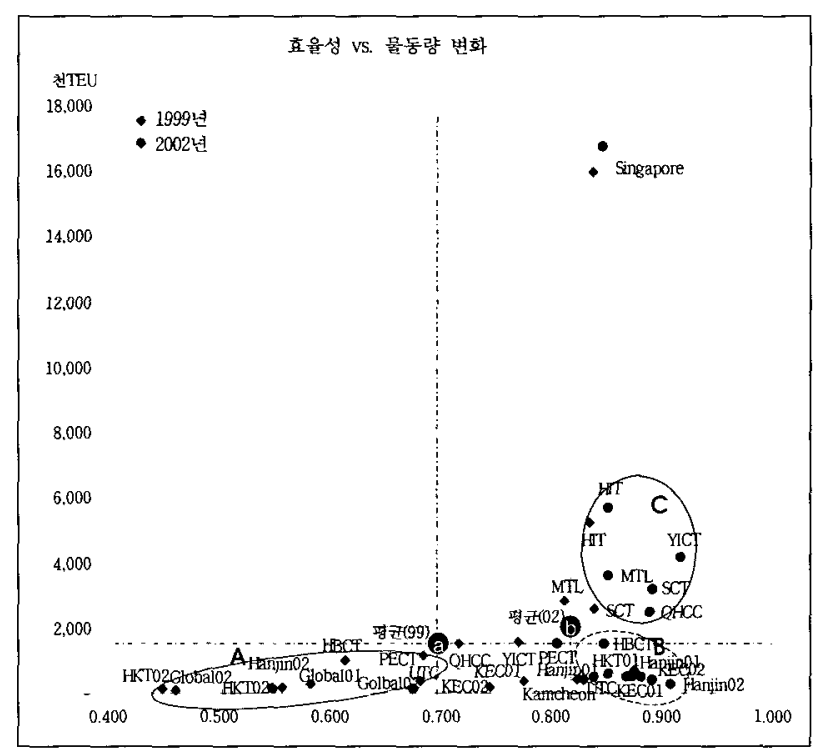

Fig. 5 Efficiency Change 1999 vs. 2002 
효율성이 높은 상위그룹으로는 HIT, YICT, SCT, QHCC, Gamman, HBCT 둥으로 나타났으며, 이중 물동량도 평균이상 인 그륩은 Singapore, HIT, YICT, SCT, MTL, QHCC 등으로 국내 터미널은 전무한 실정이다.

우리나라 컨테이너터미널의 경우 Gamman 4개 터미널과 Gwangyang KEC 및 Hanjin 터미널 등이 1999년 이후 지속 적으로 효율성이 증가하고 있다. 그러나 우리나라 터미널은 평균이상 물동량을 처리하는 터미널이 나타나고 있지 않아 중 심터미널의 위상을 점유하지 못하고 있는 것으로 판단된다.

이상의 결과로 물동량과 효율성이 높은 Cluster 1에 포함된 터미널에는 평균이상의 물동량을 처리하는 대형터미널과 비교 적 소규모 터미널이 동시에 포함되어 있다. 이것은 컨테이너 터미널의 효율성은 그 터미널의 규모에 의해 좌우되지 않는다 는 것을 시사하는 것이다.

개별터미널의 효율성을 분석한 결과 HBCT와 Gamman이 물동량 증가에 힘입어 효율성이 상위에 랭크되었고, Gwangyang항의 경우 $\mathrm{G} / \mathrm{C}$ 대수와 $\mathrm{T} / \mathrm{C}$ 대수가 적어서 적은 물동량을 처리하고도 효율성이 높게 나타나는 터미널과 그렇 지 않은 터미널로 양극화 현상이 두드러지게 나타나고 있다. 대체적으로 우리나라 터미널의 규모는 $\mathrm{HBCT}$ 와 PECT를 제 외하고 소규모 단일선석으로 운영되고 있으며, 선박대형화 및 항만대형화에 대한 환경변화에 적절히 대응하기 어려운 점이 있다.

Table 4 Comparison of Efficiency Estimation

\begin{tabular}{|c|c|c|c|c|c|c|c|}
\hline \multirow{12}{*}{ 효율성 } & \multirow{6}{*}{ 상위5 } & 순위 & 2002 & 2001 & 2000 & 1999 & 1998 \\
\hline & & 1 & YICT & $\mathrm{KECO2}$ & Hanjin01 & Gioia Tauro & Dubai \\
\hline & & 2 & Hanjin02 & YICT & $\mathrm{KECO2}$ & Dubai & Singapore \\
\hline & & 3 & Gioia Tauro & KEC01 & $\mathrm{KECOI}$ & $\mathrm{SCT}$ & CSXWT \\
\hline & & 4 & SCT & Hanjin01 & SCT & Singapore & \\
\hline & & 5 & KECO2 & OHCC & Goia Tauro & HTT & Gioia Tauro \\
\hline & \multirow{6}{*}{ 하위5 } & 순위 & 2002 & 20001 & 2000 & 1999 & 1998 \\
\hline & & 28 & Gobal02 & Cobal02 & Tokyo & Port klang & UTC \\
\hline & & 29 & SCTCN & Tokyo & Global02 & Gobal02 & YICT \\
\hline & & 30 & Tokyo & Eurogate & SCTCN & HKTO2 & $\mathrm{OHCC}$ \\
\hline & & 31 & Eurogate & SCTCN & Eurogate & SCTCN & LCB1 \\
\hline & & 32 & HKT02 & HKT02 & HKT02 & Salalah & Port klang \\
\hline \multirow{3}{*}{\multicolumn{2}{|c|}{ 특징 }} & \multicolumn{2}{|c|}{ 구 분 } & 2002 & 2001 & 1999 & 1998 \\
\hline & & \multicolumn{2}{|c|}{ Gamman } & 0.867 & 0.858 & 0.862 & 0.752 \\
\hline & & \multicolumn{2}{|c|}{ Gwangyang } & 0.755 & 0.726 & 0.623 & 0.548 \\
\hline
\end{tabular}

\section{3 국내 터미널 및 해외터미널 수준 비교}

우리나라 터미널과 해외 대상터미널의 평균효율성은 Table 5 와 같이 2001년 이후 우리나라의 평균효율성이 높게 나타나 고 있다. 1999년은 우리나라 물동량 증가세의 둔화와 Gamman, Gwangyang의 물동량이 본격화되지 않았던 시점으 로 해외 대상터미널보다 낮게 나타나고 있다.

또한, 국내터미널의 안벽길이당 처리량은 해외터미널과 비 교하여 턱없이 낮은 수준으로 나타났으며, TGS와 G/C 처리 수준에서도 해외터미널에 비해 비교적 낮은 수준을 보이고 있 지만, $\mathrm{T} / \mathrm{C}$ 처리수준예서는 국내터미널이 해외터미널보다 높게 나타나고 있다. 따라서, 국내터미널의 경우 안벽에서의 효율성 증대를 시급히 개선하여야 할 부분으로 나타났다.
Table 5 Comparison Korea vs. Oversea Terminal

\begin{tabular}{|c|c|c|c|c|c|c|}
\hline \multicolumn{2}{|c|}{ 구분 } & 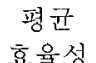 & 안벽질이 & TGS & $\begin{array}{c}\mathrm{G} / \mathrm{C} \\
\end{array}$ & T/C \\
\hline & 1998 & 0.675 & 750 & 38 & 90,587 & 35,465 \\
\hline & 1999 & 0.666 & 749 & 31 & 96,486 & 37,898 \\
\hline & 2000 & 0.734 & 905 & 36 & 115,041 & 45,698 \\
\hline & 2001 & 0.784 & 981 & 39 & 127,321 & 51,279 \\
\hline & 2002 & 0.819 & 1,126 & 44 & 133,647 & 56,731 \\
\hline \multirow{5}{*}{$\begin{array}{l}\text { 해 } \\
\text { 외 }\end{array}$} & 1998 & 0.639 & 1,004 & 37 & 111,294 & 33,355 \\
\hline & 1999 & 0.701 & 1,098 & 40 & 119,627 & 37,857 \\
\hline & 2000 & 0.754 & 1,244 & 45 & 132,102 & 42,832 \\
\hline & 2001 & 0.762 & 1,287 & 46 & 134,379 & 44,220 \\
\hline & 2002 & 0.806 & 1,465 & 52 & 154,399 & 48,978 \\
\hline
\end{tabular}

\section{5. 결론 및 한계점}

컨테이너물동량의 지속적인 증가, 항만운영에 있어서 민간참 여 확대, 글로벌 운영업체들의 급성장 및 선박과 항만의 대형화 등은 컨테이너터미널의 환경에 많은 변화를 예고하고 있다. 이 같은 컨테이너터미널 환경변화에서 개별항만 및 터미널운영업 체에서는 기반시설의 확장과 함깨 컨테이너터미널의 효율성을 지속적으로 강조하고 있다.

이런 시점에 본 연구에서는 확률프론티어 모형을 이용하여 컨테이너터미널의 효율성을 계량화하여 대상 터미널간 효율성 을 비교 분석하였다.

첫째, 실증분석의 평균 효율성을 살펴보면, 1998년 0.670, 2000 년 $0.747,2002$ 년 0.812로 증가하였다. 이것은 컨테이너터 미널의 물리적인 특성이 반영된 것이라 할 수 있다. 즉 컨테 이너터미널은 개장과 동시에 투입요소들이 설치되어 투입변수 의 변화가 없는 반면 산출요소인 컨테이너처리량이 지속적으 로 상승하여 효율성의 증가를 가져온 것이다.

둘째, 컨테이너터미널의 효율성은 터미널 규모와는 상관관 계가 낮은 것으로 나타났다. 분석결과 가장 효율적인 집단에 속하는 터미널에는 대형터미널과 소규모터미널이 혼재되어 있 어 컨테이너터미널의 효율성은 그 터미널의 크기에 따라 좌우 되지 않는 것을 알 수 있다. 이와 같은 결과는 Notteboom et al.(2000)과 Tongzon(2001)의 연구와도 일치하는 부분이다.

셋째, Gamman과 Gwangyang의 통합터미널의 효율성은 실 증분석의 개별 터미널 효율성 평균값보다 높게 나타났다. 이 것은 Gamman과 Gwangyang의 개별선석 운영보다 통합터미 널로 운영하는 것이 훨씬 효율적임이 실증되었다.

넷째, 국내터미널의 효율성은 해외 대상 터미널에 비해 높 은 것으로 나타났다. 그러나 안벽에서의 처리수준이 낮게 나 타나, 향후 국내터미널은 안벽에서의 처리수준을 높일 수 있 는 선석 및 장비 대수 보강의 필요성이 실증되었다.

그러나, 본 연구는 분석을 함에 있어 다음과 같은 한계점을 가지고 있다. 첫째, 투입된 설명변수가 종속변수인 컨테이너처 리량에 대한 설명력이 부족하여 하나의 방향성만을 제시하였 
다는 한계점이 있다. 뚫째, 비표 대상 컨테이너터미넢의 기준 의 불일치성이다. 이와 같은 한계롤 극복하기 위해 컨테이너 터미널 단위의 호율성을 분석하였지만, 싱가포르, 두바이 등의 대규모 항만이 1 개 터미넌로 처리되어 분석되었다. 향후 각 터미넗의 재무자로에 대한 패널 자료롤 토대로 효율성을 분석 하여 컨테이너터미넡을 효율적으로 운영할 수 있는 더 많은 정보롤 수집해야 할 필요가 있다.

\section{참 고 문 헌}

[1] 박경서, 김창호(2002), 은행합병이 기업여신에 미치는 영 향에 관한 연구, 금융학회지, 제7권 2호, pp.123-124.

[2] 송재영(2000), DEA/AHP롤 이용한 컨테이너 터미널 효율 성에 관한 연구, 한국해양대학교 석사학위논문, pp. 20-23.

[3] 한국컨테이너부두공단(2002), 우리나라 컨테이너부두 생 산성 향상방안 연구, pp.13-39.

[4] Aigner D. J., Lovell C. A. K. and Schmidt P.(1977), "Formulation and Estimation of Stochastic Production Models", Journal of Econometrics, Vol. 6, pp.21-37.

[5] Battese G. E. and Coelli T. J.(1988), "Prediction of Firm-Level Technical Efficiencies with a Generalized Frontier Production Function and Panel Data”, Journal of Econometrics, Vol. 38, pp.387-399.

[6] Containerisation International Yearbook(1999-2003).

[7] Cullinane K, Song D. W. and Gray R.(2002), "A Stochastic Frontier Model of the Efficiency of Major Container Terminals in Asia : assessing the Influence of Administrative and Ownership Structures", Transport Research Part A. pp.743-762.

[8] Dowd, T. J. and Leschine, T. M.(1990), "Container terminal productivity : a perspective", Maritime Policy \& Management, Vol. 17, No. 2, pp.107-112.
[9] Greene W. H.(1995), LIMDEP(Version 7.0) User's Manual, Econometric Software Inc, Castle Hill, Australia.

[10] Hayuth Y. and Roll Y.(1993), "Port Performance Comparison Applying Data Envelopment Analysis (DEA)", Maritime Policy and Management, No. 20, Vol. 2, pp.153-161.

[11] Martinez E., Diaz R., Navavro M. and Ravelo T.(1999), "A Study of the Efficiency of Spanish Port Authorities using Data Envelopment Analysis", International Journal of Transport Economics, Vol. 2, pp.237-253.

[12] Meeusen W. and Van den Broeck J.(1977), "Efficiency Estimation from Cobb Douglas Production Function with Composed Error", International Economic Review, Vol. 18, pp.435-444.

[13] Notteboom T., Coeck C. and Van den Broeck J.(2000), "Measuring and Explaining the relative Efficiency of Container Terminals by means of Bayesian Stochastic Frontier Models", Journal of Maritime Economics \& Logistics, Vol. 2, pp.83-106.

[14] Pino J. B. and Alvarez R.(2000), "Economic efficiency in Spanish Ports : some empirical evidence", Maritime Policy and Management, Vol. 27, pp.169-174.

[15] Schmidt P. and Sickles R. C.(1984), "Production Frontiers and Panel Data," Journal of Business and Economic Statistics, pp.367-374.

[16] Tongzon J.(2001), "Efficiency Measurement of Selected Australian and Other International Ports using Data Envelopment Analysis", Transportation Research Part A, Vol. 35, pp.113-128.

원고접수일 : 2004 년 10 월 28 일 원고채택일 : 2005년 1월 27일 